\title{
Peningkatan Produktivitas Pertanian Padi Untuk Kesejahteraan Masyarakat
}

\author{
Darrotul Jannah $^{1 *}$, Herani Tri Lestiana ${ }^{2}$, Dedi Junaedi ${ }^{3}$ \\ IAIN Syekh Nurjati Cirebon \\ 1e-mail: jdarrotul@gmail.com \\ 2e-mail: h.t.lestiana@gmail.com \\ 3e-mail: dejuna93@gmail.com \\ *Corresponding Author
}

\begin{abstract}
ABSTRAK
Sektor pertanian merupakan bagian penting dari aktivitas ekonomi dalam masyarakat. Sektor pertanian yang unggul berhubungan dengan terjaminnya ketahanan pangan. Ketahanan pangan merupakan faktor penting yang harus diperhatikan agar proses industrialisasi dan pembangunan ekonomi berjalan dengan baik. Jika sektor pertanian diolah dengan baik maka akan meningkatkan kesejahteraan masyarakat. Kesejahteraan memerlukan pengelolaan ekonomi yang sebaik-baiknya. Metode yang digunakan dalam penelitian ini adalah pendekatan kuantitatif. Penelitian ini bertujuan mengidentifikasi faktor-faktor yang dapat meningkatkan produktivitas diantaranya faktor tanah, modal, tenaga kerja dan manajemen produksi. Penelitian ini juga bertujuan untuk mengetahui apakah faktor-faktor tersebut mempunyai pengaruh terhadap kesejahteraan petani. Dari hasil analisis data diperoleh bahwa $86,5 \%$ faktor-faktor produktivitas pertanian memiliki pengaruh positif terhadap kesejahteraan petani. Faktor-faktor tersebut adalah faktor tanah, modal dan manajemen produksi. Adapun tenaga kerja tidak memiliki pengaruh yang signifikan terhadap tingkat kesejahteraan masyarakat.
\end{abstract}

Kata Kunci: Tanah, Modal, Tenaga Kerja, Tingkat Produktivitas, dan Kesejahteraan

\begin{abstract}
The agricultural plays an essential role in economic activities. A strong agriculture implies that food security is assured, and it is one of the important prerequisites so the process of industrialization and economic development in particular can run propoerly. If the agricultural sector is managed well, then it will improve society's welfare. The prosperity of the society requires a great management of economy. The method employed in this study quantitative approach which aims to determine some factors that can increase the productivity of agricultural sector, namely factors of land, capital, labor and production management. This study also describes the correlation of those factors and farmers' welfare. The result of data analysis shows that $86.5 \%$ of factors mentioned above have a positive influence on the welfare of farmers namely the factor of land, capital and production management. Meanwhie, labor factor has no significant influence on the welfare of farmers.
\end{abstract}

Keywords: Level of agricultural productivity, welfare 


\section{PENDAHULUAN}

Pertanian merupakan bagian penting dari aktivitas ekonomi dalam masyarakat. Ketahanan pangan sangat berhubungan dengan sektor pertanian. Sektor pertanian yang baik akan menjamin ketahanan pangan. Hal ini merupakan faktor yang penting agar industrialisasi pada khususnya dan pembangunan ekonomi melalui sektor pertanian pada umumnya bisa berjalan dengan baik dan lancar (Tambunan, 2003).

Jika pada sektor pertanian di olah dengan baik maka akan tercipta masyarakat untuk meningkatkan kesejahteraan. Kesejahteraan memerlukan keberhasilan dalam pengelolaan ekonomi yang sebaik-baiknya. Dengan dibarengi oleh pemerataan yang adil maka terjadilah kerakyatan yang sesungguhnya (Sumawinata, 2004). Suasana dimana terasa adanya keadilan dan pemerataan dimana-mana. Suasana yang dirangsang oleh adanya sikap memihak kepada yang lemah dan miskin, membawa dan memperkuat rasa sejahtera kepada rakyat. Rasa sejahtera yang timbulnya dari adanya kebebasan dari ketakutan, bebas dari tekanan-tekanan yang tidak menyenangkan, bebas dari kemiskinan dan berbagai macam kebutaan akan jauh lebih kuat terasa jika di masyarakat kelihatan adanya kecukupan barang, jasa dan lain-lain dan juga kesempatan. Karena itu kesejahteraan secara adil hanya ada jika dapat disajikan barang dan jasa untuk memenuhi kebutuhan hidup sehari-hari (Azmi, 2005). Dengan kesejahteraan aman sentosa, makmur atau selamat dengan kata lain terlepas dari segala macam gangguan, kesukaran dan sebagainya (Rusyan, dkk, 1994). Dengan kata lain kesejahteraan juga dapat dikatakan dimana suatu masyarakat dapat melakukan aktivitas ekonomi dengan baik.

Kesejahteraan ekonomi menurut Muhammad Abdul Mannan (Rozalinda, 2016) adalah meningkatnya penghasilan masyarakat yang disebabkan oleh hasil produksi yang terus meningkat karena pendayagunaan sumber daya secara optimal, baik sumber daya manusia maupun sumber daya alam. Dalam Islam, peningkatan sistem produksi tidak hanya mengacu pada penambahan penghasilan dalam bentuk uang, tetapi juga peningkatan pada terpenuhinya kebutuhan manusia dengan tetap berdasar pada tuntutan islam. Oleh karena itu, meningkatnya volume produksi tidak selalu berarti kesejahteraan masyarakat akan terjamin. Kualitas hasil produksi yang sesuai syariah islam juga harus diperhatikan dalam meningkatkan kesejahteraan masyarakat. Selain itu, akibatakibat yang merugikan dari produk-produk terlarang juga harus diperhatikan (Rozalinda, 2016). Produksi mempunyai peranan penting dalam menentukan taraf hidup manusia dan kemakmuran suatu bangsa. Keinginan untuk menciptakan kesejahteraan masyarakat seperti yang tertuang dalam pancasila/UUD 1945 serupa dengan konsep Negara Kesejahteraan. Hal ini bisa dilihat, baik dari rumusan UUD 1945 maupun UUD 1945 hasil amandemen (2002), khususnya dalam Bab XIV Pasal 33 dan 34. 
Berdasarkan uraian pendahuluan di atas, penelitian ini memfokuskan pada empat permasalahan, yaitu pertama, seberapa besar pengaruh tanah sawah dalam tingkat produktivitas padi terhadap kesejahteraan petani di Desa Kanci Kulon Kec. Astanajapura Kab. Cirebon. Kedua, seberapa besar pengaruh modal dalam tingkat produktivitas padi terhadap kesejahteraan petani di Desa Kanci Kulon Kec. Astanajapura Kab. Cirebon. Ketiga, seberapa besar pengaruh tenaga kerja dalam tingkat produktivitas padi terhadap kesejahteraan petani di Desa Kanci Kulon Kec. Astanajapura Kab. Cirebon. Dan keempat, seberapa besar pengaruh manajemen produksi dalam tingkat produktivitas padi terhadap kesejahteraan petani di Desa Kanci Kulon Kec. Astanajapura Kab. Cirebon.

\section{BAHAN DAN METODE}

Penelitian ini dilakukan di Desa Kanci Kulon Kecamatan Astanajapura Kabupaten Cirebon yang mana desa ini menjadi salah satu diantara desa di kecamatan Astanajapura yang tingkat produktivitas padi nya lebih rendah sedangkan memiliki lahan yang cukup luas diantara desa-desa lain yang mana memiliki kesamaan iklim dan cuaca pada desa-desa tersebut.

Penelitian menggunakan pendekatan kuantitatif. Dalam pendekatan kuantitatif, variablevariabel (variabel X dan Y dalam penelitian ini) diatur dan dicari keterkaitan antar variable tersebut (Kusumah, 2012). Pendekatan kuantitatif diaplikasikan untuk menelaah populasi dan sempel tertentu, dimana biasanya sampel diambil dengan cara random (random sampling) (Sugiyono, 2012). Penelitian kuantitatif juga berdasar pada aliran empirisme positivisme yang berkeyakinan bahwa kebenaran ada pada fakta-fakta yang secara empiris dapat dibuktikan atau diuji (Suharsaputra, 2012).

Penelitian ini menggunakan metode deskriptif, yaitu metode yang diaplikasikan untuk menguraikan masalah yang sedang terjadi dan untuk menggambarkan apa adanya yang terjadi selama penelitian dilakukan (Kusumah, 2012). Pada penelitian ini, metode deskriptif digunakan untuk menggambarkan suatu gejala atau fenomena tingkat produktivitas pertanian dalam hubungannya dengan kesejahteraan di Desa Kanci Kulon Kecamatan Astanajapura Kabupaten Cirebon.

Data yang diperoleh dalam penelitian ini adalah data hasil observasi, wawancara, penyebaran angket dan dokumentasi yang didapat dari para Petani di Desa Desa Kanci Kulon Kec. Astanajapura Kab. Cirebon. Populasi yang menjadi subjek dalam penelitian ini adalah petani. Sementara itu, melihat jumlah populasi petani Desa Kanci Kulon Kec. Astanajapura Kab. Cirebon yang tidak mungkin dijadikan sebagai objek penelitian penulis karena keterbatasan waktu, dana, perlengkapan maka penelitian menggunakan sampel berdasarkan pendapat Arikunto (2002), yaitu 
pengambilan sampel yang diambil untuk proses penelitian yaitu berkisar 10-15\% atau 20-25\% atau lebih. Maka sampel yang diambil oleh peneliti adalah 120 orang maka 25\% x $120=30$ petani.

\section{HASIL DAN PEMBAHASAN}

\section{Profil Wilayah Pengabdian}

1. Keadaan Geografis dan Luas Wilayah

Secara geografis Desa Kanci Kulon berada di Kabupaten Cirebon dan terdapat sungai yang membentang serta terhubung dengan laut jawa. Sedangkan secara administrative Desa Kanci Kulon mempunyai luas wilayah seluas 360,625 Ha. Desa Kanci Kulon terdiri dari 7 RW dan 25 RT. Wilayah Desa Kanci Kulon dibatasi oleh beberapa desa, yaitu:

- Sebelah barat : Kecamatan Mundu

- Sebelah timur : Desa Desa Kanci Wetan

- Sebelah utara : Laut Jawa

- Sebelah selatan : Desa Buntet

2. Iklim Desa Kanci Kulon

Seperti pada umumnya bahwa yang termasuk kedalam kabupaten Cirebon beriklim tropis, sehingga daerah ini mempunyai dua musim, yaitu musim kemarau dan musim hujan.

3. Penduduk Desa Kanci Kulon

Jumlah penduduk desa Kanci Kulon Tahun 2016 sebanyak 6.817 jiwa, yang terdiri dari lakilaki 3.263 jiwa dan perempuan 3.554 jiwa.

4. Sarana dan Prasarana

Sarana dan prasarana di Desa Kanci Kulon, yaitu: sarana perhubungan adanya jalan penghubung provinsi Kecamatan dan kabupaten, jalan aspal desa dan jalan desa bukan aspal. Sarana perekonomian di Desa Kluwut terdapat jumlah warung sembako sebanyak 72 Buah took/kios 13 buah waserda 1 buah.

\section{Deskripsi Variabel}

Berdasarkan hasil penelitian terhadap 30 responden melalui penyebaran angket, untuk mengetahui kecenderungan jawaban responden terhadap jawaban masing-masing variabel maka dipaparkan tentang skor jawaban seperti berikut:

1. Deskripsi Variabel Tanah

Pengukuran variable modal menggunakan enam pertanyaan yang menggambarkan indikatorindikator variabel tanah. Hasil angket yang diperoleh dari 30 responden dirangkum pada tabel di bawah ini. 
Tabel 1. Persentase Kategori Item Tanah (X1)

\begin{tabular}{|c|c|c|c|c|c|c|c|c|c|c|c|}
\hline \multirow{3}{*}{$\begin{array}{l}\text { No. } \\
\text { Item }\end{array}$} & \multicolumn{10}{|c|}{ Kategori } & \multirow{3}{*}{$\begin{array}{l}\text { Total } \\
(\%)\end{array}$} \\
\hline & \multicolumn{2}{|c|}{ SS (5) } & \multicolumn{2}{|c|}{ S (4) } & \multicolumn{2}{|c|}{ R (3) } & \multicolumn{2}{|c|}{ TS (2) } & \multicolumn{2}{|c|}{ STS (1) } & \\
\hline & $\mathbf{F}$ & $(\%)$ & $\mathbf{F}$ & $(\%)$ & $\mathbf{F}$ & $(\%)$ & $\mathbf{F}$ & $(\%)$ & $\mathbf{F}$ & $(\%)$ & \\
\hline 1 & 6 & 20 & 21 & 70 & 3 & 10 & 0 & 0 & 0 & 0 & 100 \\
\hline 2 & 1 & 3,33 & 5 & 16,67 & 13 & 43,33 & 8 & 26,67 & 3 & 10 & 100 \\
\hline 3 & 4 & 13,33 & 16 & 53,33 & 7 & 23,34 & 3 & 10 & 0 & 0 & 100 \\
\hline 4 & 4 & 13,33 & 13 & 43,33 & 12 & 40 & 1 & 3,33 & 0 & 0 & 100 \\
\hline 5 & 16 & 53,33 & 11 & 36,67 & 3 & 10 & 0 & 0 & 0 & 0 & 100 \\
\hline 6 & 6 & 20 & 18 & 60 & 6 & 20 & 0 & 0 & 0 & 0 & 100 \\
\hline
\end{tabular}

Sumber: Data Primer, 2018

2. Deskripsi Variabel Modal

Sama dengan variabel tanah, pengukuran variabel modal juga menggunakan enam pertanyaan yang menggambarkan indikator-indikator variabel modal. Hasil angket yang diperoleh dari 30 responden dirangkum pada tabel di bawah ini:

Tabel 2. Persentase Kategori Item Modal (X2)

\begin{tabular}{|c|c|c|c|c|c|c|c|c|c|c|c|}
\hline \multirow{3}{*}{$\begin{array}{l}\text { No. } \\
\text { Item }\end{array}$} & \multicolumn{10}{|c|}{ Kategori } & \multirow{3}{*}{$\begin{array}{l}\text { Total } \\
(\%)\end{array}$} \\
\hline & \multicolumn{2}{|c|}{ SS (5) } & \multicolumn{2}{|c|}{ S (4) } & \multicolumn{2}{|c|}{ R (3) } & \multicolumn{2}{|c|}{ TS (2) } & \multicolumn{2}{|c|}{ STS (1) } & \\
\hline & $\mathbf{F}$ & $(\%)$ & $\mathbf{F}$ & $(\%)$ & $\mathbf{F}$ & $(\%)$ & $\mathbf{F}$ & $(\%)$ & $\mathbf{F}$ & $(\%)$ & \\
\hline 1 & 4 & 13,33 & 16 & 53,33 & 7 & 23,34 & 3 & 10 & 0 & 0 & 100 \\
\hline 2 & 8 & 26,67 & 11 & 36,67 & 9 & 30 & 2 & 6,66 & 0 & 0 & 100 \\
\hline 3 & 14 & 46,67 & 12 & 40 & 4 & 13,33 & 0 & 0 & 0 & 0 & 100 \\
\hline 4 & 4 & 13,33 & 13 & 43,33 & 12 & 40 & 1 & 3,33 & 0 & 0 & 100 \\
\hline 5 & 14 & 46,67 & 13 & 43,33 & 3 & 10 & 0 & 0 & 0 & 0 & 100 \\
\hline 6 & 9 & 30 & 10 & 33,33 & 11 & 36,67 & 0 & 0 & 0 & 0 & 100 \\
\hline
\end{tabular}

3. Deskripsi Variabel Tenaga Kerja

Pengukuran variabel teknologi juga menggunakan 6 pertanyaan yang menggambarkan indikator-indikator variabel teknologi. Hasil angket yang diperoleh dari 30 responden dirangkum pada tabel di bawah ini:

Tabel 3. Persentase Kategori Item Tenaga Kerja(X3)

\begin{tabular}{|c|c|c|c|c|c|c|c|c|c|c|c|}
\hline \multirow{3}{*}{$\begin{array}{l}\text { No. } \\
\text { Item }\end{array}$} & \multicolumn{10}{|c|}{ Kategori } & \multirow{3}{*}{$\begin{array}{l}\text { Total } \\
(\%)\end{array}$} \\
\hline & \multicolumn{2}{|c|}{ SS (5) } & \multicolumn{2}{|c|}{ S (4) } & \multicolumn{2}{|c|}{$\mathbf{R}(\mathbf{3})$} & \multicolumn{2}{|c|}{ TS (2) } & \multicolumn{2}{|c|}{ STS (1) } & \\
\hline & $\mathbf{F}$ & $(\%)$ & $\mathbf{F}$ & $(\%)$ & $\mathbf{F}$ & $(\%)$ & $\mathbf{F}$ & $(\%)$ & $\mathbf{F}$ & $(\%)$ & \\
\hline 1 & 11 & 36,67 & 13 & 43,33 & 5 & 16,67 & 1 & 3,33 & 0 & 0 & 100 \\
\hline 2 & 16 & 53,33 & 11 & 36,67 & 3 & 10 & 0 & 0 & 0 & 0 & 100 \\
\hline 3 & 1 & 3,33 & 8 & 26,67 & 11 & 36,67 & 7 & 23,33 & 3 & 10 & 100 \\
\hline 4 & 1 & 3,33 & 5 & 16,67 & 13 & 43,33 & 8 & 26,67 & 3 & 10 & 100 \\
\hline 5 & 16 & 53,33 & 9 & 30 & 5 & 16,67 & 0 & 0 & 0 & 0 & 100 \\
\hline 6 & 16 & 53,33 & 9 & 30 & 4 & 13,33 & 1 & 3,33 & 0 & 0 & 100 \\
\hline
\end{tabular}


4. Deskripsi Variabel Manajemen Produksi

Variabel manajemen produksi ditinjau dengan 4 pertanyaan yang menggambarkan indikatorindikator variabel manajemen produksi. Hasil angket yang diperoleh dari 30 responden dirangkum pada tabel di bawah ini:

Tabel 4. Persentase Kategori Manajemen Produksi(X4)

\begin{tabular}{|c|c|c|c|c|c|c|c|c|c|c|c|}
\hline \multirow{3}{*}{$\begin{array}{l}\text { No. } \\
\text { Item }\end{array}$} & \multicolumn{10}{|c|}{ Kategori } & \multirow{3}{*}{$\begin{array}{l}\text { Total } \\
(\%)\end{array}$} \\
\hline & \multicolumn{2}{|c|}{ SS (5) } & \multicolumn{2}{|c|}{ S (4) } & \multicolumn{2}{|c|}{ R (3) } & \multicolumn{2}{|c|}{ TS (2) } & \multicolumn{2}{|c|}{ STS (1) } & \\
\hline & $\mathbf{F}$ & $(\%)$ & $\mathbf{F}$ & $(\%)$ & $\mathbf{F}$ & $(\%)$ & $\mathbf{F}$ & $(\%)$ & $\mathbf{F}$ & $(\%)$ & \\
\hline 1 & 4 & 13,33 & 16 & 53,33 & 7 & 23,34 & 3 & 10 & 0 & 0 & 100 \\
\hline 2 & 9 & 30 & 10 & 33,33 & 11 & 36,67 & 0 & 0 & 0 & 0 & 100 \\
\hline 3 & 9 & 30 & 11 & 36,67 & 7 & 23,34 & 3 & 10 & 0 & 0 & 100 \\
\hline 4 & 14 & 46,67 & 11 & 36,67 & 5 & 16,66 & 0 & 0 & 0 & 0 & 100 \\
\hline
\end{tabular}

5. Deskripsi Variabel Tingkat Produktivitas

Pengukuran variabel tingkat pendapatan menggunakan 6 pertanyaan yang menggambarkan indikator-indikator variabel tingkat produktivitas. Hasil angket yang diperoleh dari 30 responden dirangkum pada tabel di bawah ini:

Tabel 5. Persentase Kategori Tingkat Kesejahteraan (Y)

\begin{tabular}{|c|c|c|c|c|c|c|c|c|c|c|c|}
\hline \multirow{3}{*}{$\begin{array}{l}\text { No. } \\
\text { Item }\end{array}$} & \multicolumn{10}{|c|}{ Kategori } & \multirow{3}{*}{$\begin{array}{l}\text { Total } \\
(\%)\end{array}$} \\
\hline & \multicolumn{2}{|c|}{ SS (5) } & \multicolumn{2}{|c|}{ S (4) } & \multicolumn{2}{|c|}{ R (3) } & \multicolumn{2}{|c|}{ TS (2) } & \multicolumn{2}{|c|}{ STS (1) } & \\
\hline & $\mathbf{F}$ & $(\%)$ & $\mathbf{F}$ & $(\%)$ & $\mathbf{F}$ & $(\%)$ & $\mathbf{F}$ & $(\%)$ & $\mathbf{F}$ & $(\%)$ & \\
\hline 1 & 6 & 20 & 16 & 53,33 & 4 & 13,33 & 4 & 13,33 & 0 & 0 & 100 \\
\hline 2 & 6 & 20 & 21 & 70 & 3 & 10 & 0 & 0 & 0 & 0 & 100 \\
\hline 3 & 6 & 20 & 18 & 60 & 6 & 20 & 0 & 0 & 0 & 0 & 100 \\
\hline 4 & 10 & 33,33 & 12 & 40 & 7 & 23,34 & 1 & 3,33 & 0 & 0 & 100 \\
\hline 5 & 4 & 13,33 & 13 & 43,33 & 12 & 40 & 1 & 3,33 & 0 & 0 & 100 \\
\hline 6 & 16 & 53,33 & 9 & 30 & 5 & 16,67 & 0 & 0 & 0 & 0 & 100 \\
\hline
\end{tabular}

\section{Hasil Pengujian Instrumen}

1. Uji Validitas

Uji validitas digunakan untuk mendeskripsikan apakah instrumen atau alat ukur dalam penelitian ini dapat mengukur apa yang akan diukur secara tepat dan akurat. Untuk mengetahui validitas setiap item pernyataan, setiap variabel yang akan diuji validitasnya dikorelasikan. Suatu item dinyatakan valid apabila $r_{\text {hitung }}>r_{\text {tabel }}$, dengan $N=28$ maka diperoleh $\mathrm{r}$ tabel $=0,361$. 
Tabel 6. Uji Validitas

\begin{tabular}{|c|c|c|c|c|c|}
\hline Variabel & No & $\mathrm{N}$ & $r_{\text {hitung }}$ & $r_{\text {tabel }}$ & Keterangan \\
\hline \multirow{6}{*}{ Tanah } & 1 & 28 & 0.484 & 0.361 & Valid \\
\hline & 2 & 28 & 0.521 & 0.361 & Valid \\
\hline & 3 & 28 & 0.488 & 0.361 & Valid \\
\hline & 4 & 28 & 0.482 & 0.361 & Valid \\
\hline & 5 & 28 & 0.570 & 0.361 & Valid \\
\hline & 6 & 28 & 0.514 & 0.361 & Valid \\
\hline \multirow{6}{*}{ Modal } & 7 & 28 & 0.488 & 0.361 & Valid \\
\hline & 8 & 28 & 0.553 & 0.361 & Valid \\
\hline & 9 & 28 & 0.522 & 0.361 & Valid \\
\hline & 10 & 28 & 0.482 & 0.361 & Valid \\
\hline & 11 & 28 & 0.694 & 0.361 & Valid \\
\hline & 12 & 28 & 0.503 & 0.361 & Valid \\
\hline \multirow{6}{*}{ Tenaga Kerja } & 13 & 28 & 0.681 & 0.361 & Valid \\
\hline & 14 & 28 & 0.617 & 0.361 & Valid \\
\hline & 15 & 28 & 0.487 & 0.361 & Valid \\
\hline & 16 & 28 & 0.521 & 0.361 & Valid \\
\hline & 17 & 28 & 0.641 & 0.361 & Valid \\
\hline & 18 & 28 & 0.708 & 0.361 & Valid \\
\hline \multirow{4}{*}{$\begin{array}{l}\text { Manajemen } \\
\text { Produksi }\end{array}$} & 19 & 28 & 0.488 & 0.361 & Valid \\
\hline & 20 & 28 & 0.503 & 0.361 & Valid \\
\hline & 21 & 28 & 0.605 & 0.361 & Valid \\
\hline & 22 & 28 & 0.361 & 0.361 & Valid \\
\hline \multirow{6}{*}{$\begin{array}{c}\text { Tingkat } \\
\text { Kesejahteraan }\end{array}$} & 23 & 28 & 0.490 & 0.361 & Valid \\
\hline & 24 & 28 & 0.484 & 0.361 & Valid \\
\hline & 25 & 28 & 0.514 & 0.361 & Valid \\
\hline & 26 & 28 & 0.498 & 0.361 & Valid \\
\hline & 27 & 28 & 0.482 & 0.361 & Valid \\
\hline & 28 & 28 & 0.641 & 0.361 & Valid \\
\hline
\end{tabular}

Sumber: Data Primer, 2018

Dari hasil pengelolaan SPSS diatas, maka dapat dinyatakan bahwa secara kesulurahan setiap item pernyataan yang diajukan dinyatakan valid, karena $r_{\text {hitung }}>r_{\text {tabel }}$. Oleh karena itu 28 item yang sudah ada dapat digunakan untuk pengujian selanjutnya.

2. Uji Reliabilitas

Uji reliabilitas digunakan untuk mendeskripsikan tingkat kestabilan sebuah instrumen dalam mengukur sebuah gejala. Pengujian reliabilitas menggunakan rumus Cronbach Alpha. Jika nilai koefisien Alpha lebih > 0,6 maka bisa dikatakan pengukuran tersebut reliable. Hasil pengujian reliabilitas dalam penelitian ini ditunjukkan pada table output SPSS berikut ini. 


\section{Tabel 7. Uji Reliabilitas}

Reliability Statistics

\begin{tabular}{rrrr}
\hline Cronbach's Alpha & $\begin{array}{c}\text { Cronbach's Alpha Based on } \\
\text { Standardized Items }\end{array}$ & N of Items & \\
\hline 905 & & 909 & 28 \\
\hline
\end{tabular}

Sumber: Data Primer, 2018

Dari hasil uji reliabilitas diatas, bahwa nilai Cronbach Alpha adalah 0,905. Nilai ini lebih besar dari 0,60. Artinya variabel-variabel dalam penelitian ini sudah reliable yang dilakukan dengan menggunakan variabel independen (Tanah, Modal, Tenaga Kerja, Manajemen Produksi) terhadap Variabel dependen (Tingkat Produktivitas).

\section{Transformasi Data Ordinal ke Interval}

Kegiatan transformasi data dilakukan untuk menyesuaikan skala data yang dengan teknik analisa yang diaplikasikan. Skala data yang digunakan menggunakan skala data ordinal. Oleh karena itu, analisa regresi mensyaratkan skala pengukuran minimal interval, maka dilakukan transformasi data ordinal ke interval dengan metode MSI (Method of Successive Interval).

\section{Hasil Uji Asumsi Klasik}

\section{Normalitas}

Uji normalitas bisa digunakan bisa menggambarkan apakah data yang diperoleh berdistribusi normal atau tidak. Beberapa metode bisa digunakan dalam uji normalitas, diantaranya adalah metode Kolmogorov-Smirnov seperti yang digunakan dalam penelitian ini. Jika pada hasil uji normalitas nilai signifikansi data >0,05 maka dinyatakan normal, tetapi jika nilai signifikansi data $<0,05$ maka dinyatakan tidak normal.

Tabel 8. Uji Normalitas

\begin{tabular}{llr}
\hline \multicolumn{2}{c}{ One-Sample Kolmogorov-Smirnov Test } \\
\hline $\mathrm{N}$ & & Unstandardized Residual \\
Normal & Mean & 30 \\
Parameters ${ }^{\mathrm{a}, \mathrm{b}}$ & Std. Deviation & .0000000 \\
Most Extreme & Absolute & 1.14657962 \\
Differences & Positive & .096 \\
& Negative & .089 \\
Kolmogorov-Smirnov Z & -.096 \\
Asymp. Sig. (2-tailed) & .525 \\
\hline a. Test distribution is Normal. & .946 \\
\hline
\end{tabular}

Sumber: Data Primer, 2018 
Selain melihat nilai signifikansi, normalitas data juga bisa dilihat dari nilai KolmogorovSmirnov Test $(K-S)$. Dapat dilihat dari table di atas bahwa nilai Kolmogorov-Smirnov Test adalah 0,525 dengan nilai signifikan 0,946 . Hasil ini menunjukkan bahwa $H_{o}$ diterima, yang artinya bahwa data berdistribusi normal.

\section{Multikolinearitas}

Uji Multikolinearitas merupakan uji yang digunakan untuk menjawab pertanyaan apakah ada hubungan antara beberapa atau semua variabel dalam model regresi. Multikolinearitas dalam model menunjukkan bahwa model tersebut mempunyai kekeliruan standar yang signifikan sehingga koefisien tidak dapat ditaksir dengan ketepatan yang tinggi. Dengan ketentuan apabila nilai VIF < 10 maka model regresi yang digunakan pada penelitian ini dianggap tidak memiliki kolinearitas.

Tabel 9. Uji Multikolinearitas

\begin{tabular}{|c|c|c|c|c|c|c|c|c|}
\hline \multicolumn{9}{|c|}{ Coefficients $^{\mathbf{a}}$} \\
\hline & \multirow[b]{2}{*}{ Model } & \multicolumn{2}{|c|}{$\begin{array}{l}\text { Unstandardized } \\
\text { Coefficients }\end{array}$} & \multirow{2}{*}{$\begin{array}{c}\text { Standardized } \\
\text { Coefficients } \\
\text { Beta } \\
\end{array}$} & \multirow[b]{2}{*}{$\mathrm{T}$} & \multirow{3}{*}{$\begin{array}{c}\text { Sig. } \\
551\end{array}$} & \multicolumn{2}{|c|}{$\begin{array}{c}\text { Collinearity } \\
\text { Statistics }\end{array}$} \\
\hline & & B & Std. Error & & & & Tolerance & VIF \\
\hline 1 & (Constant) & .787 & 1.303 & & .604 & & & \\
\hline & Tanah & .867 & .131 & .849 & 6.617 & .000 & .327 & 3.058 \\
\hline & Modal & .077 & .176 & .079 & .436 & .667 & .163 & 6.144 \\
\hline & $\begin{array}{l}\text { Tenaga } \\
\text { kerja }\end{array}$ & -.068 & .086 & -.087 & -.792 & .436 & .448 & 2.234 \\
\hline & $\begin{array}{l}\text { Manajemen } \\
\text { Produksi }\end{array}$ & .144 & .231 & .096 & .622 & .540 & .224 & 4.455 \\
\hline
\end{tabular}

a. Dependent Variable: Tingkat kesejahteraan

Sumber: Data Primer, 2018

Dari hasil data diatas dapat diketahui nilai VIF pada variabel Tanah (X1) sebesar 3.058 dengan nilai tolerance 0.327 , variabel Modal (X2) sebesar 6.144 dengan nilai tolerance 0.163 , variabel Tenaga Kerja (X3) sebesar 2.234 dengan nilai tolerance 0.448 , dan variabel Manajemen Produksi (X4) sebesar 4.455 dengan nilai tolerance 0.224 ,.Hal ini menunjukkan bahwa semua variabel bebas (independen) memiliki nilai VIF < 10 sehingga dapat disimpulkan bahwa tidak adanya Multikolinearitas. 


\section{Analisis Data dan Pengujian Hipotesis Statistik}

\section{Uji Regresi Berganda}

Uji ini diaplikasikan untuk mengetahui besarnya pengaruh variabel tanah (X1), modal (X2), tenaga kerja (X3), manajemen produksi (X4), terhadap tingkat produktivitas (Y). Hubungan antara variabel-variabel tersebut dinyatakan dalam persamaan berikut.

$$
\mathbf{Y}=\alpha+b_{1} X_{1}+b_{2} X_{2}+b_{3} X_{3}+b_{4} X_{4}++e
$$

Keterangan :

$\mathrm{Y}=$ Tingkat Kesejahteraan

$\alpha=$ Konstanta

$\mathrm{X}_{1}=$ Tanah

$\mathrm{X}_{2}=$ Modal

$\mathrm{X}_{3}=$ Tenaga Kerja

$\mathrm{X}_{4}=$ Manajemen Produksi

$\mathrm{b}=$ Koefesien Regresi

$e=$ Kesalahan Prediksi/Error

Tabel 10. Analisis Regresi Berganda

Coefficients $^{\mathrm{a}}$

\begin{tabular}{|c|c|c|c|c|c|c|}
\hline \multirow{2}{*}{\multicolumn{2}{|c|}{ Model }} & \multicolumn{2}{|c|}{$\begin{array}{l}\text { Unstandardized } \\
\text { Coefficients } \\
\text { Std. }\end{array}$} & \multicolumn{3}{|l|}{$\begin{array}{l}\text { Standardized } \\
\text { Coefficients }\end{array}$} \\
\hline & & B & Error & Beta & $\mathrm{T}$ & Sig. \\
\hline \multirow[t]{7}{*}{1} & (Constant) & .787 & 1.303 & & .604 & .551 \\
\hline & Tanah & .867 & .131 & .849 & 6.617 & .000 \\
\hline & Modal & .077 & .176 & .079 & .436 & .667 \\
\hline & Tenaga & -.068 & .086 & -.087 & -.792 & .436 \\
\hline & kerja & & & & & \\
\hline & Manajemen & .144 & .231 & .096 & .622 & .540 \\
\hline & Produksi & & & & & \\
\hline
\end{tabular}

a. Dependent Variable: Tingkat kesejahteraan

Sumber: Data Primer, 2018

Jika hasil uju regresi ganda pada program SPSS dimasukkan pada persamaan di atas, maka akan diperoleh persamaan sebagai berikut.

$$
Y=0.787+0,867 X_{1}+0,077 X_{2}+(-0,068) X_{3}+0,144 X_{4}
$$

Dari persamaan di atas diperoleh koefisien regresi bernilai positif dari pengaruh tanah (X1), modal (X2), tenaga kerja (X3), manajemen produksi (X4),terhadap tingkat pendapatan (Y). Hal ini berarti bahwa : 
a. Konstanta sebesar0,787 dapat diartikan sebelum dipengaruhi variabel tanah (X1), modal (X2), tenaga kerja (X3), manajemen produksi (X4)sama dengan nol maka tingkat Kesejahteraan (Y) positif 0,787

b. Koefisien regresi $b_{1}$ sebesar 0,867 yang artinya apabila tanah (X1) meningkat maka tingkat kesejahteraan (Y) akan meningkat dengan asumsi variabel modal (X2), tenaga kerja (X3), manajemen produksi (X4) terhadap tingkat kesejahteraan (Y) dianggap konstan.

c. Koefisien regresi $b_{2}$ sebesar 0,077 yang artinya apabila modal (X2) meningkat maka tingkat kesejahteraan (Y) akan meningkat dengan asumsi variabel tanah (X1), tenaga kerja (X3), manajemen produksi (X4) terhadap tingkat kesejahteraan (Y) dianggap konstan.

d. Koefisien regresi $b_{3}$ sebesar-0,068 artinya apabila tenaga kerja (X3) meningkat maka tingkat kesejahteraan (Y) akan meningkat dengan asumsi variabel tanah (X1), modal (X2), manajemen produksi (X4) terhadap tingkat kesejahteraan (Y) dianggap tidak konstan.

e. Koefisien regresi $b_{4}$ sebesar 0,144 yang artinya apabila manajemen produksi (X4) meningkat maka tingkat kesejahteraan (Y) akan meningkat dengan asumsi variabel tanah (X1), modal (X2), tenaga kerja (X3)terhadap tingkat kesejahteraan (Y) dianggap konstan.

\section{Uji Koefisien Determinasi}

Analisis determinasi digunakan untuk mengetahui Persentase sumbangan pengaruh variabel independen secara bersama-sama terhadap variabel dependen. Koefisien ini menunjukkan seberapa besar kemampuan model dalam menjelaskan variasi variabel dependen. Nilai koefisien determinasi adalah antara nol dan satu $(0<\mathrm{R}<1)$. Semakin besar koefisien determinasinya maka semakin besar variasi variabel independennya mempengaruhi variabel dependennya.

\section{Tabel 11. Uji Determinasi}

Model Summary ${ }^{b}$

\begin{tabular}{rlrrrr}
\hline Model & \multicolumn{1}{c}{ R } & R Square & $\begin{array}{c}\text { Adjusted R } \\
\text { Square }\end{array}$ & $\begin{array}{r}\text { Std. Error of } \\
\text { the Estimate }\end{array}$ & Durbin-Watson \\
1 & $.930^{\mathrm{a}}$ & .865 & .844 & 1.235 & 2.275 \\
\hline
\end{tabular}

a. Predictors: (Constant), Manajemen produksi, Tenaga kerja, Tanah, Modal

b. Dependent Variable: Tingkat kesejahteraan

Sumber: Data Primer, 2018

Rumus yang digunakan untuk menentukan determinasi ini adalah $\mathrm{KD}=r^{2} \mathrm{x} 100 \%$. Maka nilai koefisien determinasinya adalah: 


$$
\begin{aligned}
& K D=r^{2} \times 100 \% \\
& \mathrm{KD}=(0,930)^{2} \times 100 \% \\
& \mathrm{KD}=0,865 \times 100 \% \\
& \mathrm{KD}=86,5 \%
\end{aligned}
$$

Hal ini menunjukkan sebesar 86,5\% variasi dari tingkat kesejahteraan dipengaruhi oleh faktor-faktor yaitu tanah (X1), modal (X2), tenaga kerja (X3), manajemen produksi (X4). Sedangkan sisanya $(100 \%-86,5 \%=13,5 \%)$ dijelaskan oleh variabel lain selain dari variabel yang diteliti.

\section{Uji t}

Pengaruh variabel independen secara parsial terhadap variabel dependen, yaitu untuk menggambarkan apakah ada pengaruh variabel tanah (X1), modal (X2), tenaga kerja (X3), manajemen produksi (X4) terhadap variabel tingkat kesejahteraan (Y), dapat diukur menggunakan uji t. Taraf signifikansi pada uji ini adalah 0.05 dan df $=n-2$, maka $t_{\text {tabel }}$ yang diperoleh adalah 1,70113. Hipotesis yang akan diuji adalah:

a. Ho = tidak ada pengrauh variabel bebas secara parsial terhadap variabel terikat

b. $\mathrm{Ha}=$ ada pengaruh variabel bebas secara parsial terhadap variabel terikat

Kriteria untuk Uji t sebagai berikut:

Apabila $t_{\text {hitung }}>t_{\text {tabel }}$ maka Ha diterima

\begin{tabular}{|c|c|c|c|c|c|c|}
\hline & & \multicolumn{2}{|c|}{$\begin{array}{l}\text { Unstandardized } \\
\text { Coefficients }\end{array}$} & $\begin{array}{l}\text { Standardized } \\
\text { Coefficients }\end{array}$ & \multirow[b]{2}{*}{$\mathrm{T}$} & \multirow[b]{2}{*}{ Sig. } \\
\hline \multicolumn{2}{|c|}{ Model } & B & Error & Beta & & \\
\hline 1 & (Constant) & .787 & 1.303 & & .604 & .551 \\
\hline & Tanah & .867 & .131 & .849 & 6.617 & .000 \\
\hline & Modal & .077 & .176 & .079 & .436 & .667 \\
\hline & Tenaga kerja & -.068 & .086 & -.087 & -.792 & .436 \\
\hline & $\begin{array}{l}\text { Manajemen } \\
\text { produksi }\end{array}$ & .144 & .231 & .096 & .622 & .540 \\
\hline
\end{tabular}

Apabila $t_{\text {hitung }}<t_{\text {tabel }}$ maka Ho ditolak

\section{Tabel 12. Uji T}

\section{Coefficients $^{\mathrm{a}}$}

a. Dependent Variable: Tingkat kesejahteraan

Sumber: Data Primer, 2018 
Dari hasil pemaparan diatas diketahui bahwa $t_{\text {hitung }}$ untuk variabel tanah (X1) 6.617, untuk variabel modal (X2) 0.436, untuk variabel tenaga kerja (X3) -0.792, untuk variabel manajemen produksi $(\mathrm{X} 4)$ 0.622. Untuk distribusi $t_{\text {tabel }}$ yaitu sebesar 1.701 seperti yang telah dijelaskan diatas, yang artinya bahwa variabel $X 1$ memilki $t_{\text {hitung }}>t_{\text {tabel }}$. Dengan demikian secara parsial variabel independen X1 mempunyai pengaruh secara signifikan terhadap variabel dependen Y. Dan untuk variabel X2, X3 dan X4 tidak mempengaruhi secara parsial terhadap variabel dependen $Y$ karena $t_{\text {hitung }}<t_{\text {tabel }}$. Hal ini dikarenakan persepsi petani yang ada di desa Kanci Kulon memandang bahwa modal, tenaga kerja dan manajemen produksi tidak memiliki pengaruh penting terhadap kelangsungan pekerjaan mereka, padahal dalam kenyataannya petani membutuhkan modal yang cukup untuk usahanya tenaga kerja yang ahli dan manajemen produksi yang bisa mengelola dengan baik.

\section{Uji F}

Uji F dilakukan untuk menguji variabel bebas (modal, tenaga kerja, teknologi, pengalaman dan cuaca) apakah berpengaruh signifikan secara bersama-sama (simultan) terhadap variabel terikat (dependent) yang dalam hal ini yaitu variabel tingkat pendapatan. Hasil perhitungan Uji F ini diperoleh sebagai berikut:

Tabel 13. Uji F

ANOVA $^{b}$

\begin{tabular}{|c|c|c|c|c|c|c|}
\hline \multirow[b]{2}{*}{ Model } & & \multicolumn{5}{|c|}{ Mean } \\
\hline & & Sum of Squares & df & Square & $\mathrm{F}$ & Sig. \\
\hline \multirow[t]{3}{*}{1} & Regression & 244.988 & 4 & 61.247 & 40.162 & $.000^{\mathrm{a}}$ \\
\hline & Residual & 38.125 & 25 & 1.525 & & \\
\hline & Total & 283.113 & 29 & & & \\
\hline
\end{tabular}

a. Predictors: (Constant), Manajemen produksi, Tenaga kerja, Tanah, Modal

b. Dependent Variable: Tingkat kesejahteraan

Sumber: Data Primer, 2018

Perumusan hipotesis untuk Uji F sebagai berikut:

Ho = tidak ada pengaruh variabel bebas secara simultan terhadap variabel terikat

$\mathrm{Ha}=$ ada pengaruh variabel bebas secara simultan terhadap variabel terikat.

Dengan kriteria uji hipotesis sebagai berikut:

Apabila $F_{\text {hitung }}>F_{\text {tabel }}$ maka Ho ditolak Ha diterima

Apabila Sig hitung $_{>}$0,05 maka Ho diterima dan Ha ditolak

Apabila Sighitung $<0,05$ maka Ho ditolak dan Ha diterima 
Dari hasil tabel diatas menunjukkan bahwa nilai $F_{\text {hitung }}$ sebesar 40.162. Nilai $F_{\text {hitung }}$ dibandingkan dengan $F_{\text {tabel }}$. Mencari $F_{\text {tabel }}$ dilakukan dengan menggunakan tingkat signifikansi 5\%, df1 (jumlah variabel - 1) dan df2 (n - k - 1), dimana n adalah jumlah kasus dan $\mathrm{k}$ adalah jumlah variabel independen. Berdasarkan hasil tersebut, diperoleh nilai $\mathrm{F}_{\text {tabel }}$ sebesar 2.56. Hasil analisis data menunjukkan bahwa nilai $F_{\text {hitung }}>F_{\text {tabel }}$ yaitu $40.162>2.56$, maka dapat disimpulkan bahwa Ho ditolak dan Ha diterima. Dalam hal ini dijelaskan bahwa variable tanah, modal, tenaga kerja, dan manajemen produksi secara bersama-sama mempunyai pengaruh terhadap tingkat produktivitas terhadap kesejahteraan petani.

\section{KESIMPULAN DAN SARAN}

Berdasarkan hasil penelitian yang telah dilakukan pada variabel tanah, modal, tenaga kerja, dan manajemen produksi terhadap tingkat produktivitas padi terhadap kesejahteraan petani di Desa Kanci Kulon Kecamatan Astanajapura Kabupaten Cirebon, maka dapat disimpulkan bahwa :

1. Berdasarkan perhitungan bahwa faktor produksi tanah menunjukkan hasil analisis data menggunakan Uji Regresi bahwa variabel tanah (X1) memiliki pengaruh produktivitas padi sebesar 0.867 atau sebesar $86,7 \%$ terhadap Tingkat kesejahteraan petani(Y).

2. Berdasarkan perhitungan bahwa faktor produksi modal menunjukkan hasil analisis data menggunakan Uji Regresi bahwa variabel modal (X2) memiliki pengaruh produktivitas padi sebesar 0.077 atau sebesar 7,7\% terhadap Tingkat kesejahteraan petani (Y).

3. Berdasarkan perhitungan bahwa faktor produksi tenaga kerja menunjukkan hasil analisis data menggunakan Uji Regresi bahwa variabel tenaga kerja (X3) tidak memiliki pengaruh ialah sebesar -0.068 atau sebesar $-6,8 \%$ terhadap Tingkat kesejahteraan petani (Y).

4. Berdasarkan perhitungan bahwa faktor produksi manajemen produksi menunjukkan hasil analisis data menggunakan Uji Regresi bahwa variabel manajemen produksi (X4) memiliki pengaruh produktivitas padi sebesar 0.144 atau sebesar $14.4 \%$ terhadap Tingkat kesejahteraan petani (Y).

Dengan demikian berdasarkan hasil analisis data menggunakan Uji Determinasi pengaruh variabel tanah, modal, tenaga kerja dan manajemen produksi pada tingkat produkivitas padi mempunyai pengaruh terhadap kesejahteraan petani sebesar 86,5\%. Berdasarkan hasil perhitungan Uji F didapat nilai F hitung sebesar 40.162 dengan nilai signifikan 0.000, kemudian $\mathrm{F}$ table sebesar 2.56. Maka hal ini menunjukkan positif, bahwa $\mathrm{F}_{\text {hitung }}>\mathrm{F}_{\text {tabel }}$. Dengan demikian dapat dinyatakan variabel tanah, modal, tenaga kerja dan manajemen produksi secara simultan berpengaruh signifikan pada tingkat produktivitas padi terhadap kesejahteraan petani. 


\section{UCAPAN TERIMA KASIH}

Terima kasih disampaikan kepada:

1. Kepala Desa Kanci Kulon, Kecamatan Kanci, Kabupaten Cirebon

2. Masyarakat petani Desa Kanci Kulon, Kecamatan Kanci, Kabupaten Cirebon

\section{DAFTAR PUSTAKA}

Arikunto, S. (2002). Prosedur Penelitian: Suatu Metode Pendekatan Praktek. Jakarta: Rineka Cipta.

Azmi, S. (2005). Menimbang Ekonomi Islam. Bandung: Penerbit Nuansa.

Barthos, B. (1990). Manajemen Sumber Daya Manusia: Suatu Pendekatan Makro. Jakarta: Penerbit Bumi Aksara.

Bungin, B. (2005). Metodologi penelitian kuantitatif. Jakarta: Kencana Prenada Media Group.

Bûthî, M. S. Î. R. A. (1992). Dhawâbith al-Mashlahah fì al-Syarî'ah al-Islâmiyyah. Bayrût: Dâr al-Muttahidah.

Fauzia, I. Y. \& Riyadi, A. K. (2014). Prinsip Dasar Ekonomi Islam Perspektif Maqashid alSyariah. Jakarta: Kencana.

Hasibuan, I. Y., Bangun, P., \& Sinulingga, U. (2014). Analisis Faktor yang Mempengaruhi Tingkat Produksi Padi Sawah di Kabupaten Padang Lawas. Saintia Matematika, 2(4), 323332.

Kusumah, Y. (2012). Pengaruh Supervisi Klinis oleh Kepala Sekolah Terhadap Kinerja Mengajar Guru di SMA Al-Ma'soem Jatinangor (Skripsi, Universitas Pendidikan Indonesia).

Martono, N. (2012). Metode Penelitian Kuantitatif: Analisis Isi dan Analisis Data Sekunder. Jakarta: PT. Raja Grafindo Persada.

Murdiantoro, B. (2011). Faktor-Faktor yang Mempengaruhi Produksi padi di Desa Pulorejo Kecamatan Winong Kabupaten Pati (Skripsi, Universitas Negeri Semarang).

Nasution, M. E. (2017). Pengenalan Eksklusif Ekonomi Islam. Jakarta: Kencana.

Pusat Pengkajian dan Pengembangan Ekonomi Islam (P3EI). (2008). Ekonomi Islam. Jakarta: RajaGrafindo Persada.

Rozalinda. (2016). Ekonomi Islam Teori dan Aplikasinya pada Aktivitas Ekonomi. Jakarta: Rajawali Press.

Rusyan, A.T, dkk. (1994). Pendekatan dalam Proses Belajar Mengajar. Bandung: PT

Sugiyono. (2012). Metode Penelitian Bisnis (Cetakan ke-16). Bandung: Penerbit Alfabeta.

Suharsaputra, U. (2012). Metode penelitian kuantitatif, kualitatif, dan tindakan. Bandung: Refika Aditama. 
Sumawinata, S. (2004). Politik Ekonomi Kerakyatan. Jakarta: Gramedia Pustaka Utama. Suprayitno, E. (2008). Ekonomi Mikro: Perspektif Islam. UIN-Maliki Press.

Tambunan, T. (2003). Perkembangan Sektor Pertanian di Indonesia. Ghalia Indonesia. 